\title{
Effect of Blood Groups and Complications on Orofacial Measurements of B Thalassemia Adult Patients
}

\author{
Nada Hashim Mohammed ${ }^{1}$, Nawal Mustafa Abdullah ${ }^{2}$, Riad Altaee ${ }^{3}$ \\ 1Lec./MB,ChB, MSc Anatomy, Department of Anatomy/Al Zahraa College of Medicine, University of Basrah, \\ ${ }^{2}$ Assist- Prof/MB,ChB, MSc, PhD Anatomy, Department of Anatomy/Al Zahraa College of Medicine, University of \\ Basrah, ${ }^{3}$ Assistant Prof/B.D.S, College of Dentistry/University of Basrah
}

\begin{abstract}
Background: $\beta$ - thalassaemia is a common hereditary disorders in Iraq and worldwide .with different treatment schemes, including blood transfusion, iron chelation and splenectomy, patients with B thalassemia may develop different skeletal changes. Limited studies link these complications with orofacial changes, This study aimed to evaluate the orofacial dimensions in $\beta$ - thalassemia patients with age, gender, blood groups, splenectomy and cholecystectomy and to assist surgeons for planning their future intervention.

Method: This study was conducted on 130 ß-thalassemia patients of both gender,,and two age categories (20$30 \mathrm{yrs}), \&$ (21-40 yrs), five orofacial measurements (face,eyes,nose, mouth and ears) and sixteen parameters were measured and calculated for differences,P value is estimated,data analysis were done by using Chi square test and SPSS version 20

Results: Significant findings were found for mandibular width and mouth width at older age group (31-40 years), the nasal width and ear height are more in male, patients with splenectomy have significance for lower $1 \backslash 3$ face and ear width. Cholecystectomy increase eye length measurments and ear height but for blood groups the $\mathrm{P}>0.05$

Conclusions: Orofacial bone changes are pronounced in $\beta$ - thalassaemia with distinct findings regarding sex dimorphism, older are more prone to have variations, earlier splenectomy is advisable,cholecystectomy is better choice for symptomatic patients, blood groups have no significance.
\end{abstract}

Keywords: BThalassemia,,Blood groups, Orofacial measurments, Complications.

\section{Introduction}

Thalassemia are group of single gene inherited hematological disorders caused by deficiencies in the synthesis of hemoglobin chains that cause haemolytic anemia. [1] - B-thalassemia major is the most severe form leading to severe anemia in infancy or childhood

\section{Corresponding Author:}

Nawal Mustafa Abdullah

Assist- Prof/MB,ChB, MSc, PhD Anatomy, Department of Anatomy/Al Zahraa College of Medicine,

University of Basrah

e-mail: nawal.abdullah@uobasrah.edu.iq and used to be life threatening in absence of regular red cell transfusions ${ }^{[2]}$. Various studies found that patients with blood group $\mathrm{O}$ are more risky to develop $\beta$ thalassemia ${ }^{[3,4]}$. The common symptoms of the disease include severe anemia, poor growth, delayed sexual maturation,splenomegaly and gall bladder bilirubin stones, if patients are symptomatic, they may require laproscopic cholecystectomy, could be at the same time as the splenectomy. ${ }^{[5-8]}$

Patients with $\beta$ thalassemia commonly have skeletal abnormalities including limbs,vertebral column,skull and bones of the face, commonly called squirrel -like face ${ }^{[9]}$. Theorofacial bone changes are the results of ineffective erythropoiesis, the bones become thinner with pathological fractures may occur due to overexpansion 
of the bone marrow and extra medullary region and this is frequently noticed in patients who receive insufficient or irregular blood transfusions ${ }^{[10,11]}$. Patient survival depends on regular blood transfusions and iron chelating therapy,In spite of being an effective cure but there are many serious associated long-term problems. Iron toxicity (hemosiderosis) will lead to hepato splenomegaly which end with organ damage,surgical intervention and impaired growth ${ }^{[12,13]}$.

Different orofacial dimensions include face, eyes, nose, mouth and ears of thalassemia patients have significant differences from normal individuals which is documented in many studies ${ }^{[14,15]}$ Although $\mathrm{B}$ thalassemia is a leading health problem in Basrah, southern of Iraq but limited published data were available on orofacial measurements therefore the aim of the study is to evaluate the effect of age,gender, blood groups, splenectomy and cholecystectomy on orofacial bone changes and determine their clinical outcome in thalassemia patients .

\section{Material and Method}

The present study was conducted during the period from August 2019 to March 2020, data obtained from a total number of 130 adult B Thalassemia Major Iraqi patients from Basrah city ( 72 female and 58 male) who attended to the thalassemia center for Hereditary Blood diseases at Basrah Maternity and Child Hospital irrespective to their social or educational backgrounds .All patients were diagnosed previously based on hemoglobin electrophoresis or high-performance liquid chromatography and submitted to frequent blood transfusions. The age ranged between 20-40 years. Patients were divided according to age into two groups, 21-30 age group, and 31-40 age group. Patient's data including age, sex, weight (in $\mathrm{kg}$ ), and height (in $\mathrm{cm}$ ), were obtained and evaluated. All patients receive different treatments and blood transfusion.

Verbal consent obtained from each participantin this study and the approval of the Ethical Committee of Al Zahraa Medical College/University of Basrah and Centre for Human Development of Basrah Health Authority (Ref. No. 261 at 13/5/2019\} was obtained . The standard instruments used in this study were calipers and measuring tape, Fig. $1 \& 2$

Surface landmarks were marked on the face before taking the standard anthropometric measurement according to Farkas method ${ }^{[16]}$. The head orientation was achieved by positioning the head in Frankfurt horizontal plane aligned parallel to the floor. Three anatomical landmarks determined the facial midline: the nasion, the subnasal, and the gnathion. "Fourteen linear and two angular measurement taken, these are:.

1. Face: Face width (zy- zy), Face height (n- gn), Upper face height (n- sto), Maxillary depth (t- sn), Mandibular depth (t-gn).

2. Nose: Nose width (al- al), Nose height (n- sn), Nasal tip protrusion (sn- prn)

3. Eyes: Biorbital width (ex-ex), Intercanthal distance (en- en), Palpebral fissure length (en- ex).

4. Mouth: Mouth width (ch- ch), Lower lip height (sto1s), Upper lip height (sn- sto).

5. Ears: Ear width (par- pa), Ear length (sa- sba).

Facial measurments are taken in millimeters.

A comprehensive analysis of data was achieved by using SPSS version 20 and Chi square test

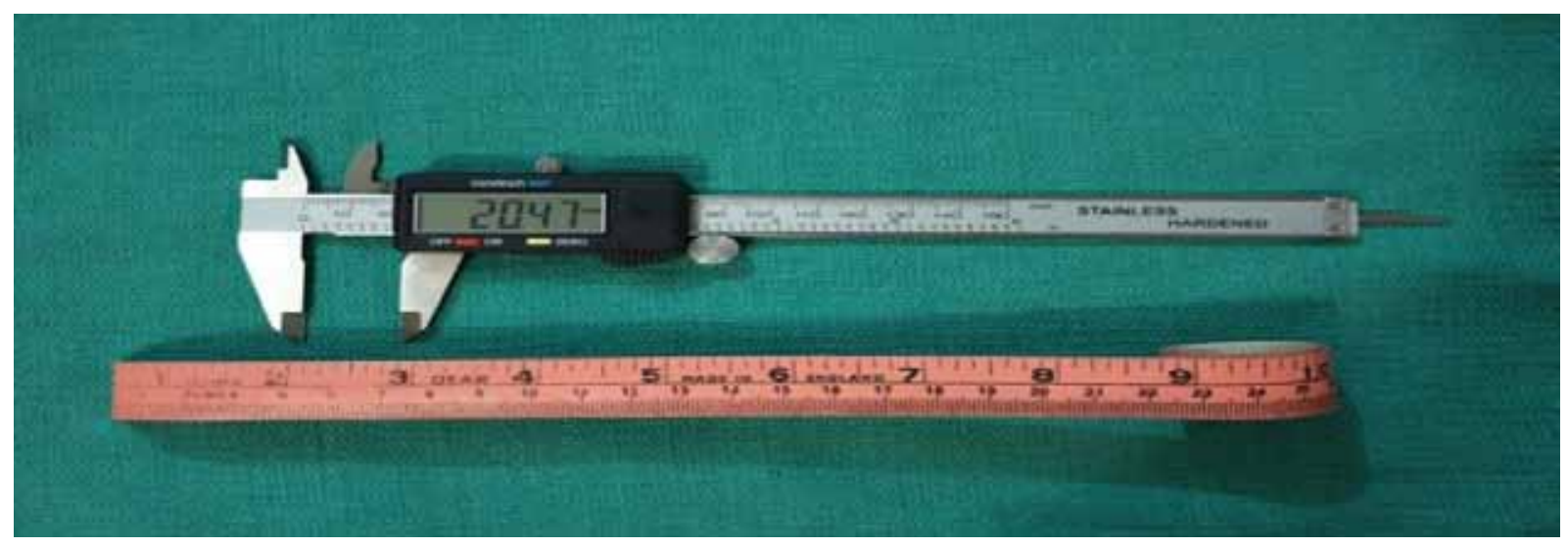

Fig. 1: The vernia and measuring tape 

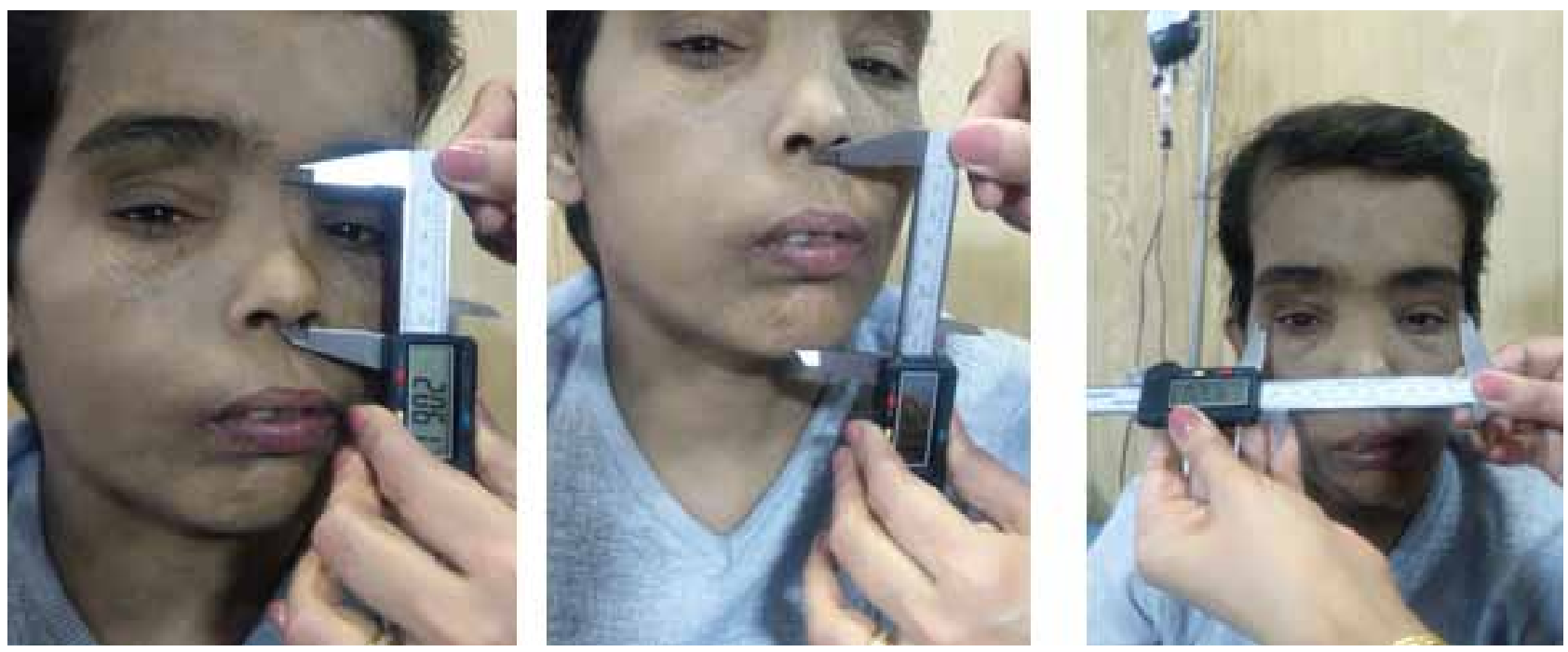

Fig. 2: Orofacial measurments

\section{Results}

A total number of $130 \mathrm{~B}$ - thalassemia adult patients of both gender ( 72 male/58 female; $1.2 / 1)$,age range from 20 to 40 years were enrolled in this study for estimating orofacial measurments (OFM).
Significant differences were found between different age groups regarding face, ear, eye, and nose, the mandibular depth (t-gn) show high results at age group $31-40$ years $(p=0.022)$ and the mouth width $(\mathrm{ch}-\mathrm{ch})$ show significance at older age group also $(p=0.041)$. Table 1.

Table 1: Relation of age to OFM of B thalassemia patients

\begin{tabular}{|c|c|c|c|c|}
\hline \multirow{2}{*}{ OFM } & & \multicolumn{2}{|c|}{ Age Group } & \\
\hline & & 20-30 & 31-40 & \\
\hline \multirow{5}{*}{ Face } & Face width (zy-zy) & 96.1 & 99.3087 & 0.129 \\
\hline & Facial height (n-gn) & 107.1111 & 107.8261 & 0.801 \\
\hline & Upper facial Morphological height (n-sto) & 68.7944 & 72.3957 & 0.099 \\
\hline & Maxillary depth (t-sn) & 117.1278 & 118.9174 & 0.505 \\
\hline & Mandibular depth (t-gn) & 128.0472 & 135.7652 & 0.022 \\
\hline \multirow{3}{*}{ Nose } & Nasal width (al-al) & 34.9139 & 35.4783 & 0.527 \\
\hline & Nasal height (n-sn) & 48.0222 & 51.3783 & 0.083 \\
\hline & Nasal length (sn-pr n) & 14.7778 & 17.2391 & 0.136 \\
\hline \multirow{2}{*}{ Mouth } & Mouth width (ch-ch) & 42.8556 & 45.6696 & 0.041 \\
\hline & Lower third face height (sn-gn) & 59.0222 & 58.0826 & 0.616 \\
\hline \multirow{3}{*}{ Eye } & Outer eye space (ex-ex) & 90.8333 & 91.1261 & 0.94 \\
\hline & Inner corner eye space (en-en) & 33.3306 & 34.0174 & 0.344 \\
\hline & Eye length (en-ex) & 30.6806 & 31.5 & 0.373 \\
\hline \multirow{2}{*}{ Ear } & Ear width (pra-pa) & 36.6861 & 37.1261 & 0.785 \\
\hline & Ear Height (sa-sba) & 54.9417 & 56.4917 & 0.367 \\
\hline
\end{tabular}

$\mathrm{P}<0.05$ is significant 
No significant differences were detected between male and female in orofacial measurement, except for nasal width (al-al), and ear height (sa-sba) which show higher results in male patients $(\mathrm{p}=0.019),(\mathrm{p}=0.011)$ respectively Table 2 .

Table 2: Relation of Sex and Orofacial measurements of B thalassemia patients

\begin{tabular}{|c|c|c|c|c|}
\hline \multirow{2}{*}{ OFM } & & \multicolumn{2}{|c|}{ Sex } & \multirow{2}{*}{ P-value } \\
\hline & & Female & Male & \\
\hline \multirow{5}{*}{ Face } & Face width (zy-zy) & 96.5364 & 98.3846 & 0.377 \\
\hline & Facial height (n-gn) & 105.9182 & 109.2577 & 0.228 \\
\hline & Upper facial Morphological height (n-sto) & 69.0091 & 71.7077 & 0.211 \\
\hline & Maxillary depth (t-sn) & 115.2303 & 121.1192 & 0.022 \\
\hline & Mandibular depth (t-gn) & 129.1515 & 133.4731 & 0.199 \\
\hline \multirow{3}{*}{ Nose } & Nasal width (al-al) & 34.2485 & 36.2577 & 0.019 \\
\hline & Nasal height (n-sn) & 48.5212 & 50.3577 & 0.338 \\
\hline & Nasal length (sn-pr n) & 16.3364 & 14.9769 & 0.405 \\
\hline \multirow{2}{*}{ Mouth } & Mouth width (ch-ch) & 43.5515 & 44.4615 & 0.509 \\
\hline & Lower third face height (sn-gn) & 57.3091 & 60.3654 & 0.093 \\
\hline \multirow{3}{*}{ Eye } & Outer eye space (ex-ex) & 89.7 & 92.5308 & 0.455 \\
\hline & Inner corner eye space (en-en) & 33.0182 & 34.3346 & 0.062 \\
\hline & Eye length (en-ex) & 30.7303 & 31.3423 & 0.498 \\
\hline \multirow{2}{*}{ Ear } & Ear width (pra-pa) & 37.2667 & 36.3385 & 0.557 \\
\hline & Ear Height (sa-sba) & 53.6942 & 57.8962 & 0.011 \\
\hline
\end{tabular}

$\mathrm{P}<0.05$ is significant

Relation of different blood groups and orofacial parameters were insignificant for all parameters (face, nose, ear, eyes and ears) as shown in Table 3.

Table 3: Comparison between blood groups of $B$ thalassemia patients and orofacial measurments

\begin{tabular}{|c|c|c|c|c|c|}
\hline \multirow{2}{*}{ OFM } & & \multicolumn{3}{|c|}{ Blood group } & \multirow{2}{*}{ P-value } \\
\hline & & A & B & $\mathbf{O}$ & \\
\hline \multirow{5}{*}{ Face } & Face width (zy-zy) & 97.4048 & 97.7941 & 96.9381 & 0.947 \\
\hline & Facial height (n-gn) & 107.9714 & 108.3 & 106.0714 & 0.775 \\
\hline & Upper facial Morphological height (n-sto) & 71 & 71.4059 & 68.419 & 0.464 \\
\hline & Maxillary depth (t-sn) & 116.3905 & 118.4529 & 118.7524 & 0.716 \\
\hline & Mandibular depth (t-gn) & 130.7143 & 130.6 & 131.7667 & 0.952 \\
\hline \multirow{3}{*}{ Nose } & Nasal width (al-al) & 34.1095 & 36.4353 & 35.1048 & 0.096 \\
\hline & Nasal height (n-sn) & 49.2857 & 50.5059 & 48.4238 & 0.685 \\
\hline & Nasal length (sn-pr n) & 16.9143 & 14.4353 & 15.6143 & 0.472 \\
\hline \multirow{2}{*}{ Mouth } & Mouth width (ch-ch) & 43.6952 & 43.9118 & 44.2429 & 0.945 \\
\hline & Lower third face height (sn-gn) & 58.6524 & 57.7588 & 59.3857 & 0.778 \\
\hline \multirow{3}{*}{ Eye } & Outer eye space (ex-ex) & 89.5429 & 92.6412 & 90.981 & 0.808 \\
\hline & Inner corner eye space (en-en) & 33.6762 & 33.2059 & 33.8381 & 0.768 \\
\hline & Eye length (en-ex) & 31.3571 & 31.7588 & 30.0286 & 0.253 \\
\hline \multirow{2}{*}{ Ear } & Ear width (pra-pa) & 36.9762 & 36.3059 & 37.1857 & 0.9 \\
\hline & Ear Height (sa-sba) & 55.9286 & 55.7118 & 55.029 & 0.897 \\
\hline
\end{tabular}


In evaluating the effect of splenectomy on OFM, significant difference was detected for the lower third face height (sn-gn) $p=0.04$ and ear width (pra-pa) $p=0.053$. Table 4.

Table 4: Relation of OFM of B thalassemia patient and splenectomy

\begin{tabular}{|c|c|c|c|c|}
\hline \multirow{2}{*}{ OFM } & & \multicolumn{2}{|c|}{ Splenectomy } & \multirow{2}{*}{ P-value } \\
\hline & & -ve & + ve & \\
\hline \multirow{5}{*}{ Face } & Face width (zy-zy) & 97.6 & 97.0 & 0.779 \\
\hline & Facial height (n-gn) & 107.3 & 107.5 & 0.926 \\
\hline & Upper facial Morphological height (n-sto) & 69.9 & 70.5 & 0.78 \\
\hline & Maxillary depth (t-sn) & 118.8 & 116.8 & 0.442 \\
\hline & Mandibular depth (t-gn) & 132.6 & 129.4 & 0.337 \\
\hline \multirow{3}{*}{ Nose } & Nasal width (al-al) & 35.6 & 34.6 & 0.226 \\
\hline & Nasal height (n-sn) & 50.3 & 48.3 & 0.283 \\
\hline & Nasal length (sn-prn) & 14.3 & 17.3 & 0.066 \\
\hline \multirow{2}{*}{ Mouth } & Mouth width (ch-ch) & 44.4 & 43.4 & 0.454 \\
\hline & Lower third face height (sn-gn) & 56.9 & 60.6 & 0.04 \\
\hline \multirow{3}{*}{ Eye } & Outer eye space (ex-ex) & 93.0 & 88.6 & 0.244 \\
\hline & Inner corner eye space (en-en) & 33.7 & 33.5 & 0.706 \\
\hline & Eye length (en-ex) & 31.1 & 30.8 & 0.74 \\
\hline \multirow{2}{*}{ Ear } & Ear width (pra-pa) & 38.3 & 35.3 & 0.053 \\
\hline & Ear Height (sa-sba) & 56.7 & 54.3 & 0.159 \\
\hline
\end{tabular}

$\mathrm{p}<0.05=$ Significant

Table 5 show significant difference for cholecystectomy and orofacial measurements regarding eye length (enex) $(\mathrm{p}=0.000)$ and ear height $(\mathrm{p}=0.019)$.

Table 5: Relation of cholecystectomy to OFM of B thalassemia patients

\begin{tabular}{|c|c|c|c|c|}
\hline \multirow{2}{*}{ OFM } & & \multicolumn{2}{|c|}{ Cholecystectomy } & \multirow{2}{*}{ P-value } \\
\hline & & -ve & $+\mathrm{ve}$ & \\
\hline \multirow{5}{*}{ Face } & Face width (zy-zy) & 97.8 & 92.1 & 0.118 \\
\hline & Facial height (n-gn) & 107.8 & 102.8 & 0.31 \\
\hline & Upper facial Morphological height (n-sto) & 70.6 & 65.8 & 0.215 \\
\hline & Maxillary depth (t-sn) & 118.0 & 116.0 & 0.665 \\
\hline & Mandibular depth (t-gn) & 131.3 & 129.0 & 0.704 \\
\hline \multirow{3}{*}{ Nose } & Nasal width (al-al) & 35.1 & 36.0 & 0.545 \\
\hline & Nasal height (n-sn) & 49.6 & 46.3 & 0.333 \\
\hline & Nasal length (sn-pr n) & 15.9 & 13.6 & 0.422 \\
\hline \multirow{2}{*}{ Mouth } & Mouth width (ch-ch) & 44.1 & 42.5 & 0.53 \\
\hline & Lower third face height (sn-gn) & 58.9 & 56.4 & 0.452 \\
\hline \multirow{3}{*}{ Eye } & Outer eye space (ex-ex) & 91.8 & 81.9 & 0.142 \\
\hline & Inner corner eye space (en-en) & 33.7 & 32.6 & 0.372 \\
\hline & Eye length (en-ex) & 31.5 & 26.1 & 0.000 \\
\hline \multirow{2}{*}{ Ear } & Ear width (pra-pa) & 37.4 & 31.1 & 0.021 \\
\hline & Ear Height (sa-sba) & 56.1 & 49.2 & 0.019 \\
\hline
\end{tabular}




\section{Discussion}

The ultimate cure of transfusion dependent thalassemia is bone marrow transplantation, but this is very costly procedure for the majority of patients, their survival, therefore, depends on regular blood transfusions and iron chelating drugs It was found that severe anemia, frequent blood transfusion,,iron over load and chelation drug toxicities and bone changes are common complications of this hereditary disease ${ }^{[17,18] \text {. }}$ The pathogenesis of skeletal changes is still unclear in spite of the enhanced treatment, patients used to have derange in bone mineral turnover with raised resorption rates and inhibition of osteoblast action which result in diminished bone mineral density (BMD) clearly evident asosteoporosis in the vertebrae,skull and face ${ }^{[13,19]}$.

The results of the current study showed that the number of male affected by thalassemia are higher than females ( $\mathrm{M}: 1.3 \backslash \mathrm{F}: 1)$. However the differences were not significant. Our study is consistent with a study of Baghianimoghadam et al. 2011, and Hannan et al,2018 ${ }^{[20.21]}$, bone changes are more common in older age group,(31-40 years old) for mandibular depth $(135.76 \mathrm{~mm})$ and mouth width $(45.66 \mathrm{~mm})$ as in Table 1 Furthermore the study found that the relation of sex and orofacial measurments were significant in patients with B thalassemia, the facial variations of nasal width (36.25) and ear height (57.89) are higher in male than female Table 2.

Bone changes in adult thalassemia patients can be explained on the bases that chronic anemia increases erythropoietin secretion, lead to bone marrow expansion and thinning of bony cortices beside overloaded iron interferes with growth of osteoid and deposited in hydroxyapatite crystals thus effecting the normal bone mineralization furthermore desferoxamine (iron chelator) prevents DNA synthesis, proliferation, and maturing of fibroblasts and osteoblasts which enhance the skeletal deformities in thalassemia ${ }^{[22,23]}$. Different blood groups have no significant effect in changing craniofacial parameters as shown in table 3.

Splenectomy result in minor changes on orofacial parameters in thalassemia patients, differences were seen for lower third face $(60 \mathrm{~mm})$ and ear width $(35.3 \mathrm{mmL})$ when compared with those without splenectomy as in Table 4 . Spleen is most commonly affected organ in $\mathrm{B}$ thalassemia due to excessive destruction of abnormal red blood cells, extra medullary hematopoiesis, and transfusion overload. The splenectomy definitely reduce blood need therefore improve hemoglobin level but seems to have prolonged orofacial changes ${ }^{[24,25]}$. In severe cases bone changes could be minimized when splenectomy is done as early as possible.

Cholelithiasis (gallstones) is well known complication in patients with thalassemia major: (TM) .Several possible explanations for this observation, including older age, high degree of ineffective erythropoiesis, whenever symptoms found, cholecystectomy must be done with follow up to prevent complications like obstructive jaundice and cholangitis ${ }^{[26]}$. Table 5 showed significant effect of cholecystectomy on orofacial measurements regarding eye length $(\mathrm{p}=0.00)$ and ear height. $(\mathrm{p}=0.019)$.

Further studies may assist in better understanding of the pathogenetic mechanism underlying bone anomalies in B thalassemia patients and it is needed to develop useful treatment therapy like use of bisphosphonate in early osteoporosis which is an effective regime to minimize the severity of skeletal complications, newgeneration of iron chelators may reduce the negative effects of deferoxamine on bone metabolism. and to improve the nutritional,hormonal deficits with the help of physical training programs.

\section{Conclusion}

The screening for carriers, premarital regulatory rules and counseling programs, can help in decreasing the incidence rate and complications although a high prevalence of thalassemia in Basrahsouthern Iraq was observed, Results had shown sex dimorphism,older age groups are prone to have obvious bony changes, earlier splenectomy is advisable in severe cases, cholecystectomy is done whenever symptoms are found, ABO blood groups have no remarkable changes on OFM.

Acknowledgment: The authors would like to thank all doctors and medical staff of Thalassemia center for Hereditary Blood diseases at Basrah Maternity and Child Hospitalfor theirgreat help and support during data collection .

Source of Funding: Self funding

Conflict of Interest: No conflict of interest.

\section{References}

1. Sacide Karakas1, Ayfer Metin Tellioglu1, Mehmet Bilgin2, Imran Kurt Omurlu3, Sercin Caliskan2, 
Salih Coskun4." Craniofacial Characteristics of Thalassemia Major Patients" Eurasian j of medicine, 2016;48:204-8.

2. Ghanshyam Gupta1, Manali Arora2" Association of orofacial features of $\beta$ thalassemia major patients " J. Evolution Med. Dent. Sci./Vol. 7/Issue 30/2018;eISSN- 2278-4802, pISSN- 2278-4748/

3. Pranoti A. Sinha ${ }^{1 *}$, Sachin H. Mulkutkar ${ }^{1}$, J. B. Bhavani“"Study of distribution of ABO blood groups in B-thalassemia patients" "International Journal of Research in Medical Sciences 2017;5(8):34793483

4. Sarah M. Mahmoud Marbut*, Maha A. Hamdi**, AbdulhadiM.Jumaa**, Basma Abbas Salman"Distribution of ABO blood groups in beta thalassemia patients dependent on blood transfusion In Bagdad city" J of madentAlelem college "2018; Vol 10 No 22

5. Alireza Jafari Naimi, Samaneh Bolourian, 2 Mahsa Mohammadzadeh, 3 Mona Farahmand, 4 Fatemeh Ghanbari5 and Sadegh Samiee6; Investigating the relationship between major thalassemia diseases with anthropometric sizes head and facial soft tissue" Bioscience Biotechnology Research communications 10(2): 233-240 (2017)

6. Abu Alhaija ESJ, Hattab FN, Al Omari MAO. Cephalometric measurements and facial deform in subjects with $\beta$-thalessaemia major. Eur J Orthod 2002; 24: 9-19.

7. Raffaella Origa1, Renzo Galanello1, Lucia Perseu2, Dario Tavazzi3, M. Domenica Cappellini3, Laura Terenzani4, Gian Luca Forni4, Giovanni Quarta5, Tatiana Boetti6, Antonio Piga6 Cholelithiasis in thalassemia major European Journal of Haematology ISSN 0902-4441

8. Weledji EP. Benefits and risks of splenectomy. Int J Surg 2014; 12:113-119.

9. Toman HA, Nasir A, Hassan R, Hassan R. Skeletal, dentoalveolar, and soft tissue cephalometric measurements of Malay transfusion-dependent thalassemia patients .Eur J Orthod 2011; 33: 700-4.

10. Bushra Moiz a, Aysha Habiba, Sobiya Sawanib, Ahmed Raheema, Bilal Hasanc and Manesh Gangwanic Anthropometric measurements in children having Transfusion dependent beta thalassemia "Hematology, 2018 Vol. 23, No. 4, 248-252, https://doi.org/10.1080/10245332.2017.1 396044.
11. Mahachoklertwattana, V. Sirikulchayanonta, A. Chuansumrit et al., "Bone histomorphometry in children and adolescents with $\beta$-thalassemia disease: iron-associated focal osteomalacia, " Journal of Clinical Endocrinology and Metabolism, vol. 88, no. 8, pp. 3966-3972, 2003.View at: Publisher Site|

12. Valizadeh N, Farrokhi F, Alinejad V, et al. Bone density in transfusion dependent thalassemia patients in Urmia Iran. Iran J Ped Hematol Oncol. 2014;4(2):68-71

13. Hashemi A, Ghilian R, Golestan M, et al. The study of growth in thalassemic patients and its correlation with Serum ferritin level. SSUJ. 2011;1(4):147151.

14. F Amini, A Jafari L Eslamian S, Sharifzadeh; A cephalometric study on craniofacial morphology of Iranian children with beta-thalassemia major; 2007 (Dentistry, Oral Surgery \& Medicine)https://doi. org/10.1111/j.1601-6343.2007.00380.x.

15. Bassimitci S, Yücel Eroglu E, Akalar M. Effects of thalassemia major on components of the craniofacial complex Br J Orthod 1996; 23: 157-162.

16. Farkas LG, Kolar JC, Munro IR. Craniofacial disproportions in Apert's syndrome: an anthropometric study. Cleft Palate J. 1985; 22:25365.

17. Tahir H, Shahid SA, Mahmood KT. Complications in thalassemia patients receiving blood transfusion. J Biomed Sci Res. 2011;3(1):339-46.

18. Haidar R, Musallam KM, Taher AT. Bone disease and skeletal complications In patients with beta thalassemia major. Bone. 2011; 48(3):425-432.17. [15]

19. Porter J, editors. Guidelines for the management of transfusion dependent thalassaemia (TDT). Nicosia (CY): Thalassemia International Federation; 2014.

20. Baghianimoghadam B, Heshmati H. Health related quality of life in children with thalassemia assessed on the basis of SF -20 questionnaire in yazd, Iran: Ascae -control study center. Eur J Public Health 2011;19:165-9.

21. Hanan Jassim Hammodi Tahanaa Abdul Mahdi Mokif, Hassan Jassim Al Harbi Mohanad Salam Majeed. Evaluation of some Biochemical and Endocrine profile In transfusion dependent Iraqi major $\beta$-thalassemia patients; Iraqi Journal of Science, 2017, Vol. 58, No. 2A, pp: 639-645 
22. Cappellini MD, Cohen A, Porter J, et al. Guidelines in the managements of transfusion dependent thalassemia; Thalassaemia International Federation; ch2 2014.

23. Hassan K, Younus M, Ikram N, Naseem L, Zaheer HA. Red cell Alloimmunization in repeatedly transfused thalassemia major patients. Int J Pathol. 2004;2(1):16-9.

24. Saleh Hatem A, Alkhateep Yahia M, Mohammed Ashraf N; Role of splenectomy in thalassemic pa tients: 2018| Volume: 31 |Issue Number: 1| Page: 118-125
25. Ikramullah Khan Akhtar, Muhammad Ashraf, and Khalid Mukhtar Surgical outcome of spelenectomy in Thalassemia major in children, Pak J Med Sci;2016 Mar-Apr; 32(2): 305-308

26 Abdulkareem A. Jasim1, Israa Mustafa Salih ALMusawi2, *, Zahraa Alaa Abdul Zhara3 Frequency of Cholelithiasis in Sickle Cell Disease and Thalassemic Patients at Hereditary Blood Diseases Center in Karbala Teaching Hospital for Children IJPPR 2018 Vol.:11, Issue:3. 